\title{
Towards a 'City in Nature': Evaluating the cultural ecosystem services approach to support urban green space management
}

\author{
Yi Fan Koh ${ }^{1}$, Ho Huu Loc ${ }^{2,3 *}$, Edward Park1,4*
}

1 National Institute of Education, Nanyang Technological University, Singapore

2 Water Engineering and Management, School of Engineering and Technology, Asian Institute of Technology, Thailand

3 Department of Environment Management, Faculty of Food and Environment Management, Nguyen Tat Thanh University, Vietnam

4 Asian School of the Environment, Nanyang Technological University, Singapore

* Correspondence: hohuuloc@ait.asia (HHL) and edward.park@nie.edu.sg (EP)

\begin{abstract}
Cultural ecosystem services has been increasingly influential in both environmental research and policy decision-making, such as for urban green spaces However, its popular definition conflates the concepts of 'services' and 'benefits' which made it challenging for planners to employ it directly for urban green space management. One the most widely used definition of this nontangible ecosystem services are "functions of environmental spaces and cultural activities which may then result in the enjoyment of cultural ecosystem benefits"; yet the latter itself have never found its way into official laws and regulations. In this study, via a case study in Singapore, we propose new evidence to re-evaluate and re-position the two of the most important emerging concepts in managing the green spaces in urban areas. Using the transdisciplinary mixed methods of public participation GIS and social media text mining analysis, a wealth of cultural ecosystem services and their associated benefits were reported. This was especially so with regards to recreational and aesthetic services and experiential benefits. Recommendations to improve the park were also suggested, alongside sharing of methodological considerations for future research. Overall, this paper recommends the employment of the redefined cultural ecosystem services conceptual framework to generate relational, data-driven and actionable insights to better support urban green space management, which is not only useful to Singapore governments but also world-wide relevant.
\end{abstract}

Keywords: Cultural ecosystem services, urban green space management, Singapore, public participation geographic information system, social media text mining analysis

\section{Introduction}

Cultural ecosystem services (CES) have been an increasingly influential concept with established literature in environmental research and policy decision-making [1-5], especially urban green space (UGS) research and planning (Baumeister et al. 2020 as its interaction motivator $[5,6]$. CES has been widely and popularly defined as "the nonmaterial benefits people obtain from ecosystems" by the Millennium Ecosystem Assessment (MA) [7]. However, such a definition has proved to be problematic for urban planners to directly incorporate CES into decision-making [8] due to the conflation of the distinct concepts of 'services' and 'benefits'. Tandarić et al. (2020), thus, proposed a more nuanced redefinition of CES to better aid academic research and policy planning [6]. Firstly, CES is defined as a function of both the environmental spaces and cultural practices. Secondly, human-nature interactions of CES may be affected by cultural values held by people on the ecosystem and affect the causal enjoyment of cultural ecosystem benefits (CEB) that enhances human well-being [9]. Such decoupling has also been echoed by many researchers to better translate CES concept into practice $[6,10]$ 
With a long withstanding history of UGS planning implicitly underlain by the concept of ecosystem services [11], Singapore has a significant opportunity to further CES research into practice. The significance of Singapore is further augmented by 'City in Nature'vision which aim "to provide Singaporeans with a better quality of life [through engaging with CES and enjoying of CEB], while co-existing with flora and fauna on this island" [12]. The new vision includes intensifying nature and greenery in new and existing local parks with the incorporation of natural designs and plantings, naturalisation of water features and conservation of important biodiversity (Lee, 2020). These developments are evident in Bishan-Ang Mo Kio Park (BAMKP)with its concrete canals transformed into natural rivers' [12] and its "wide array of interesting fauna and flora" (National Parks Board [13]. BAMKP has also been slated for further rewilding, with more naturalistic landscapes that enhance biodiversity [14].

Using BAMKP as a case study research area, this paper seeks to evaluate the operability of Tandarić et al.'s (2020) redefined CES conceptual framework in supporting UGS management to support Singapore's 'City in Nature' vision [6]. Specifically, this paper will report on the CES, CEB and cultural values of BAMKP via public participation geographic information system (PPGIS) and social media text mining analysis.

Moreover, the contextual significance of Singapore gearing towards the new 'City in Nature' vision positions this paper as very timely in supporting planners in Singapore with insights for future development and re-naturalization of UGS and complements the Natural Capital Singapore project spearheaded by the Singapore government to "assess the current status and health of Singapore's major ecosystems and quantify their economic and societal value" [15]. This paper also seeks to bridge the geographical gap in CES literature. Except for China, very few Asian countries have been publishing CES research in quantity comparable to the west [16]. Besides, current CES research in tropical Asia tends to focus on the rural environments [17] despite the region's rapid urbanization which heightens the importance of urban CES research [9, 18-21]. Therefore, findings from this paper could potentially be extrapolated to support UGS planning in the other urbanized or urbanizing tropical Asian countries.

\section{Research Area}

Located central of Singapore within Bishan town and flanked by Ang Mo Kio town on its northern edge, BAMKP (see Figure 1) was first constructed in 1988 as a 52 ha Bishan Park with a separate 2.7-kilometre-long concrete canal [22] (Dreiseitl et al., 2015). It underwent a revamp between 2009 and 2011 that overhauled the entire park with significant enhancements to park features, nature and biodiversity [22]. The reopened BAMKP in 2012 is one of Singapore's largest urban parks spanning an increased area of 62 ha with a 3-kilometre-long naturalized and meandering Kallang River. Most of the blue water features concentrate towards the south of the park whereas the northern region is predominantly green with trees and plants. BAMKP is also conveniently bisected into two smaller and distinctly featured parks by a traffic road, with the River Plains in the east and Pond Gardens in the west (refer to Supporting Information Figure S1).

While the regional park predominantly serves residents in its immediate neighbourhood, it remains attractive for Singaporeans residing further away [22]. BAMKP, with almost 6 million visitors per year, is ousting Singapore's globally famed Gardens by the Bay (5.1 million visitors per year) and the Botanical Gardens (4.4 million visitors per year). Despite its relatively smaller park size, BAMKP has almost twice the number of visitors per hectare per year as compared to the other two popular parks (Dreiseitl et al., 2015). 
BAMKP is plugged into Singapore's extensive and growing nation-wide Park Connector Network (PCN) that links different parks and green spaces in Singapore together. BAMKP is part of the Central Urban Loop and serves as a central node of the latest Coast-to-Coast (C2C) Trail that widely spans diagonally across the island from the west to the northeast $[23,24]$.

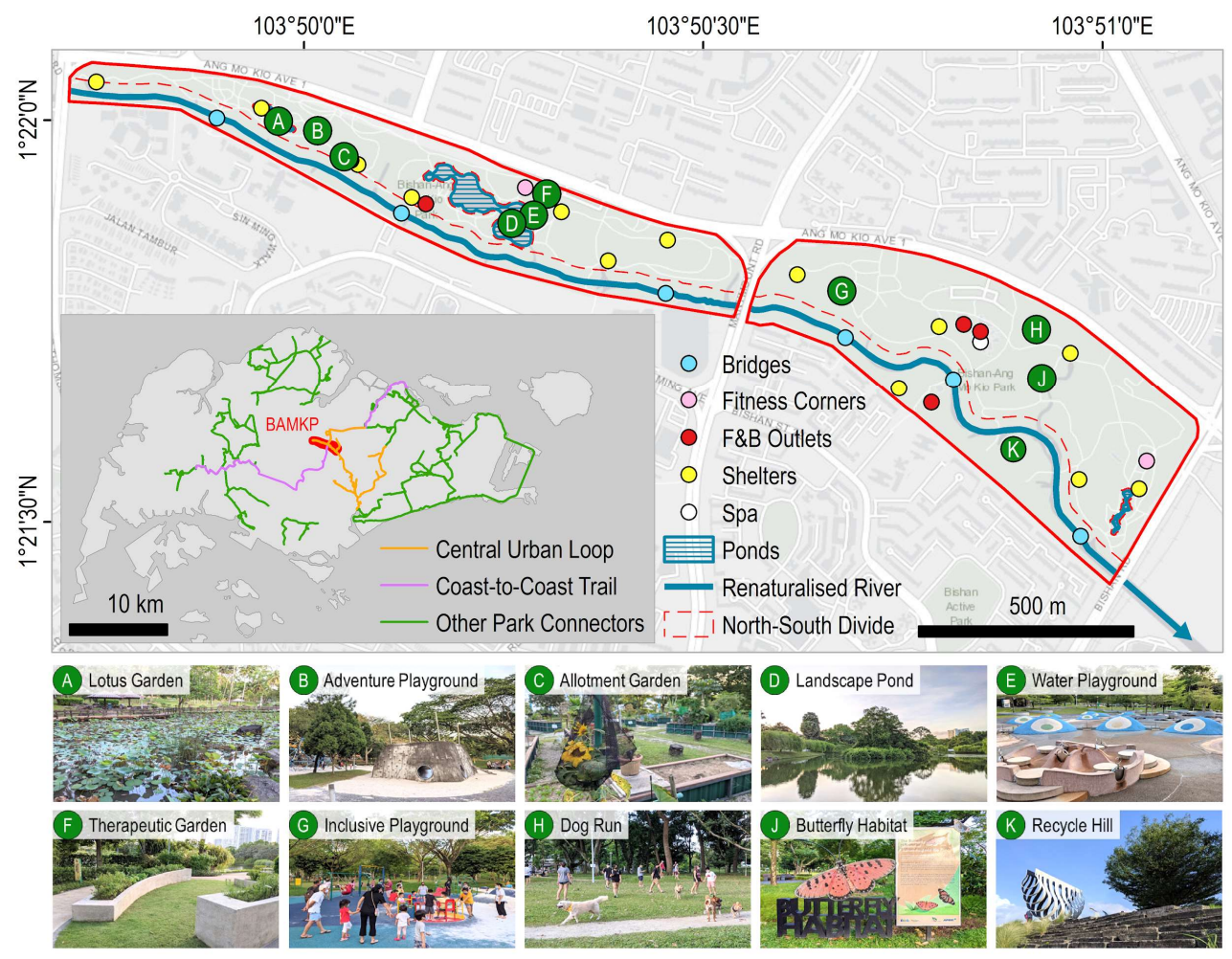

Figure. 1. Research area of Bishan-Ang Mo Kio Park with its key park features. The red dashed line divides the park into the greener and more vegetated north and blue-green south richer in water features, such as the renaturalised river and ponds (see Table 2). The inset map shows the central location of the park amidst the network of park connectors in Singapore.

\section{Methodology}

\subsection{Separating Ecosystem Services and Ecosystem Benefits}

To evaluate the operability of Tandarić et al.'s (2020) redefined CES conceptual framework (see Figure 2) to support Singapore's 'City in Nature' vision, the nuanced framework would serve as the backbone of the research methodology of this study [6]. The online PPGIS surveys served as the primary method to uncover the spatial distribution and cultural values of CES, presence of CEB and urban environmental spaces in BAMKP. The decoupling of CES and CEB in PPGIS studies would further augment its credibility and usefulness for planning and decision-making [25]. 


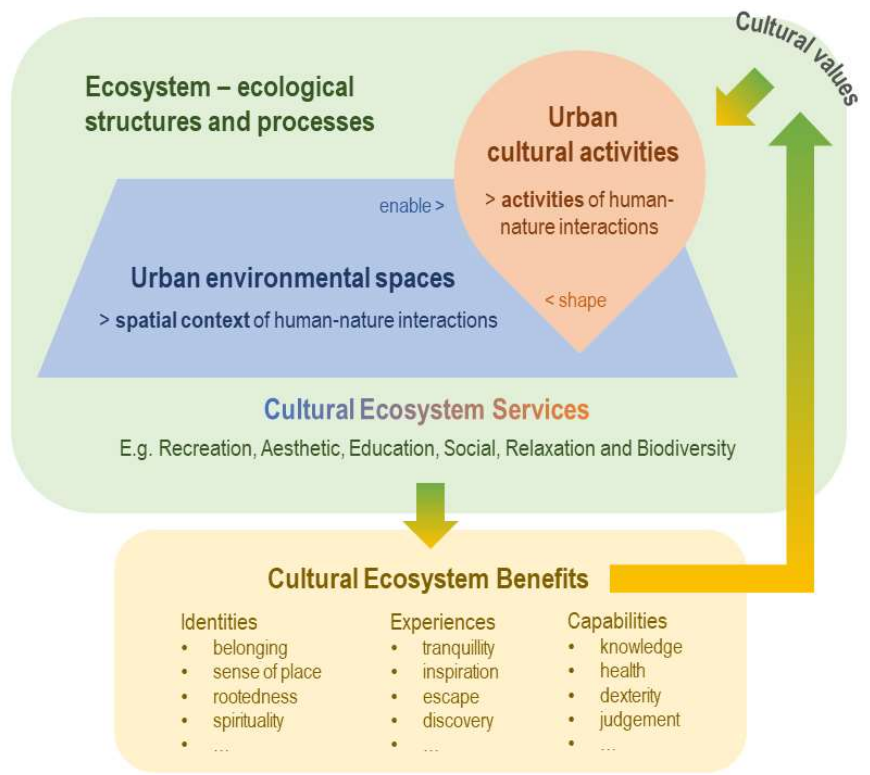

Figure 2. Redefined CES conceptual framework (Tandarić et al., 2020). Cultural ecosystem services are decoupled functions of human cultural activities taking place in environmental spaces. Its provision may be affected by cultural values held by people which will influence how they choose to interact with an ecosystem. Its presence may then also generate cultural ecosystem benefits enjoyed by people. This may in turn influence the cultural values perceived and in extension, the cultural ecosystem services provided in a continuous process. Cultural values refer to how positive or negative an ecosystem is generally perceived.

As mixed methods have been deemed more advantageous in exposing truer cultural valuations of places [25], social media text mining analysis through Google reviews of BAMKP served as the secondary mode of analysis. The analysis of public reviews will highlight the relative presence of CES and CEB in BAMKP alongside cultural values via sentiment analyses. Analysis of social media content in CES research has been popularly performed through photographs although texts have been emerging as another unique medium [26]. Social media text mining analysis method is advantageous as a rapid and cost-effective assessment of CES [27]

\subsection{Public Participation Geographic Information System (PPGIS)}

\subsubsection{Data Collection}

PPGIS was conducted through a 20-questions online survey via Map-Me [28] and Google Forms (refer to Supporting Information Method S1). 100 valid participants, who were verified to be at least 21 years old and have ever visited BAMKP, were recruited from October to November 2020. Random convenience sampling was employed where participants were reached via word of mouth through email and social media platform, starting and extending from the acquaintances of the researchers. For the spatial questions on Map-Me, participants responded by mapping out blobs on a curated map. There is no limit in the number of blobs afforded to the participants, to encourage truer and fuller responses to the spatial questions. Ground truthing was also carried out in September 2020 to ensure that the key park features were still present and georeferenced accurately on the Map-Me survey map (refer to Supporting Information Figure S1). A total of six CES and three CEB that were relevant and of interest to BAMKP were selected for the survey (see Table 1) based on both Tandarić et al.'s (2020) CES conceptual framework and previously conducted studies [13, 22]. 


\subsubsection{Data Analysis}

For data visualisation and interpretation, descriptive statistics were used to highlight the data spread through graphical representations, specifically bar and lollipop charts. Inferential statistics was performed through one-way ANOVA tests to identify statistically significant differences. For the spatial data collected, CES heat maps were created using the Point Density geoprocessing tool from ArcMap 10.4 for hotspot analysis where the concentration of CES presence would be identified and further analysed. Using the CES heat maps with equal intervals, spatial correlation using the Jaccard's Index [29] was also calculated by dividing the CES-mapped area over the total land area to determine the level of spatial correlation between each CES. CES densities along the characteristically different north-south and east-west regions of BAMKP were also calculated to expose possible regional differences of CES present. As the blue water features predominate in the southern region, the north-south segregation helps to test for the effectiveness of these blue water features in augmenting CES presence in BAMKP. The east-west segregation follows the existing division of BAMKP into the western Pond Gardens and eastern River Plains [13]. Heat maps of CES spatial distribution relating to a high degree of CEB enjoyment were also generated. Using the CES mapped blobs of participants who have reported a high score of 4.5 for each CEB, three CES-CEB point density heat maps were generated for each CEB. The score of 4.5 was optimally thresholded based on a sensitivity analysis conducted, to ensure the generation of meaningful heat maps for analysis (see Supporting Information Figure S2).

\subsection{Social Media Text Mining Analysis}

\subsubsection{Data Collection}

This paper conducted a text mining analysis on Google reviews of BAMKP since it provided the most direct and predominantly textual public opinions of BAMKP in a sheer quantity incomparable with the rest $(n=5,762$ reviews as of 17 November 2020). All the textual Google reviews of BAMKP up till 17 November 2020 were first extracted using ScrapeHero (https://www.scrapehero.com/marketplace/google-reviews/) before the data was cleaned and processed using the R software [30]. Reviews with non-English or no textual reviews were first removed before the remaining review sentences were split into individual words. Misspelt, non-English and less meaningful stop wordswere then removed, resulting in 2,356 unique words for further analysis.

\subsubsection{Data Analysis}

The resultant unique words were then analysed through occurrence frequency analysis to determine the degree of presence of CES and CEB, and sentiment analysis to expose cultural values of BAMKP. Occurrence frequency analysis was conducted by associating the same six CES and three CEB of interest with the resultant unique words before conducting a word frequency count. The classification indicators for the six CES and three CEB was established based on the following definitional criteria (see Table 1). Sentiment analysis of the cultural values was also performed using the $\mathrm{R}$ software [30] with the lexicons "AFINN" [31] and "NRC" [32] to expose the degree of positiveness or negativeness, and emotions captured in the Google reviews respectively. 
Table 1 List of relevant CES and CEB for this study and the related words for text mining analysis.

\begin{tabular}{|c|c|c|c|}
\hline & Categories & Description & Word Examples \\
\hline \multirow{6}{*}{ 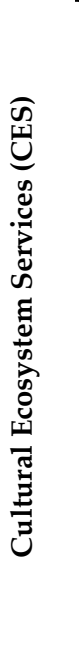 } & Recreation & $\begin{array}{l}\text { Park allows enjoyment of recreational } \\
\text { activities. }\end{array}$ & playground, cycle, dog \\
\hline & Aesthetic & $\begin{array}{l}\text { Park allows admiration of natural or man- } \\
\text { made beauty. }\end{array}$ & beautiful, scenic, clean \\
\hline & Education & $\begin{array}{l}\text { Park allows learning about nature and } \\
\text { environment. }\end{array}$ & learn, sciences, guide \\
\hline & Social & $\begin{array}{l}\text { Park allows socialisation with people, } \\
\text { family and friends. }\end{array}$ & picnic, gathering, kids \\
\hline & Relaxation & $\begin{array}{l}\text { Park allows relaxation and unwinding } \\
\text { from everyday life. }\end{array}$ & relax, stroll, refreshing \\
\hline & Biodiversity & $\begin{array}{l}\text { Park allows getting near or watching } \\
\text { animals and plants. }\end{array}$ & trees, otters, kingfisher \\
\hline \multirow{3}{*}{ 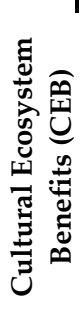 } & Identities & $\begin{array}{l}\text { Park is beneficial in shaping personal } \\
\text { identities. }\end{array}$ & spiritual, personal, past \\
\hline & Experiences & $\begin{array}{l}\text { Park is beneficial in providing positive } \\
\text { experiences. }\end{array}$ & fun, social, enjoyable \\
\hline & Capabilities & $\begin{array}{l}\text { Park is beneficial in enhancing capabilities } \\
\text { of people. }\end{array}$ & health, career, learning \\
\hline
\end{tabular}

\section{Results}

\subsection{Sociodemographic and Park Usage}

Of the 100 valid participants who completed the online PPGIS survey, most of them were aged $21-30$ years old (81\%) and of Chinese ethnicity (89\%)due to the digital focus of the survey, coupled with its promotion via word of mouth on social media platforms among the younger and predominantly Chinese demographics. Most of the participants $(83 \%)$ have identified themselves as irreligious, Buddhists or Christians and a majority of them $(88 \%)$ have attained a relatively high education level of a Bachelor's degree, Junior College certificate or postgraduate degree. Gender-wise, there were also slightly more female $(59 \%)$ than male $(41 \%)$ participants (refer to Supporting Information presented in Figure S3).

As for the participants' park usage patterns (see Figure 3), most of them have recently visited the park within the past year $(70 \%)$ but only $13 \%$ of participants have visited the park weekly in the past year. Participants generally spent a moderate average of 30-60 minutes in BAMKP (49\%) and $47 \%$ of them came with their friends (47\%). The participants' residential proximities to BAMKP, as proxied by their postal codes in relation to Singapore's postal district zones (Urban Redevelopment Authorities, n.d.), were found to be distributed in a relatively balanced manner. 
A.

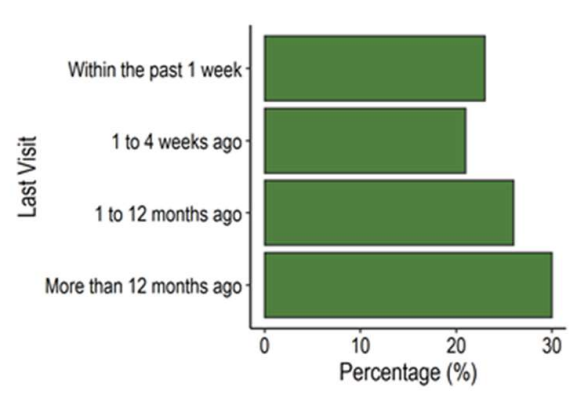

c.

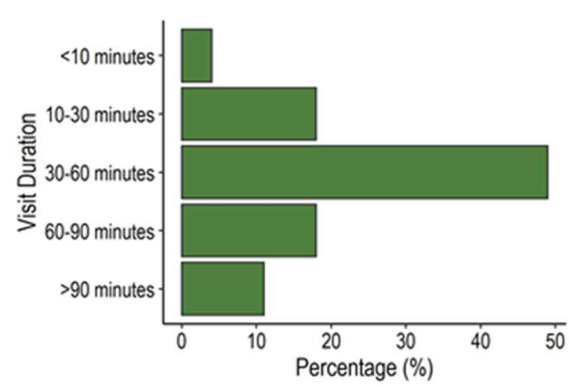

B.

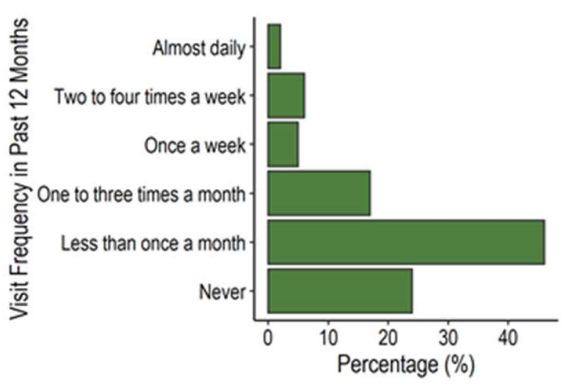

D.

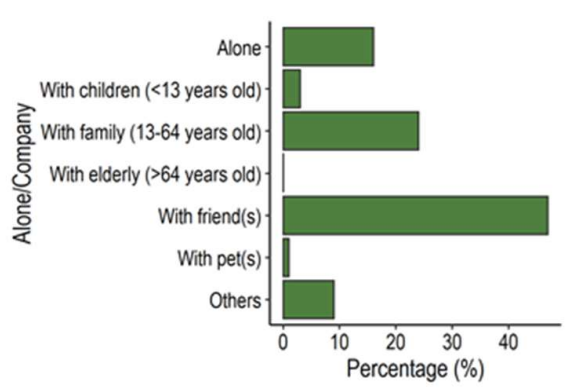

E.

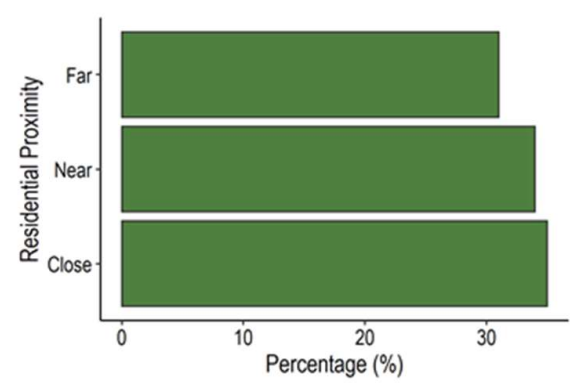

Figure 3. Park usage patterns of PPGIS participants. A. Graph of participants' last park visit. B. Graph of participants' park visit frequency in the past 12 months. C. Graph of participants' average park visit duration. D. Graph of participants' usual accompaniment for park visits. E. Graph of participants' residential proximity to the park

\subsection{Cultural Values}

Generally, findings from the sentiment analysis of Google reviews has yielded that the public's cultural values towards the park were highly positive (see Figure 4). Using the "AFINN" lexicon in $\mathrm{R}$ [31], $93.9 \%$ of the review words were associated with positive connotations, with $58.9 \%$ of them valued at least $\mathrm{a}+3$ or above. Using "NRC" as another lexicon in $\mathrm{R}$ that performs sentiment analysis more emotively [32], 84.8\% of the review words were associated with positive emotions such as joy, trust, anticipation, and surprise, with the emotion of joy being the most significant (31.7\%). 
A.

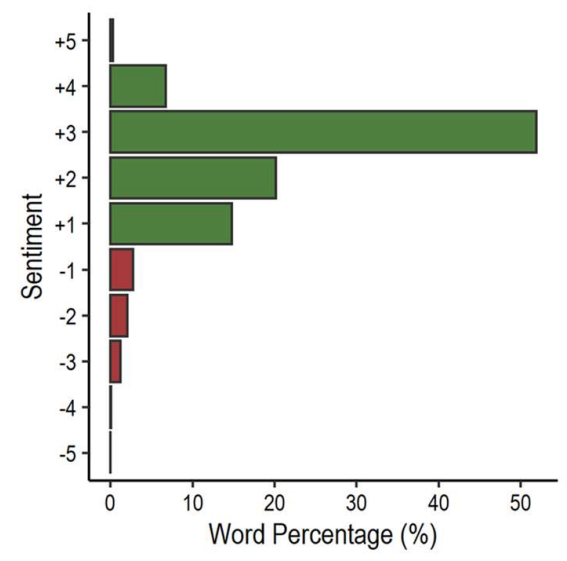

B.

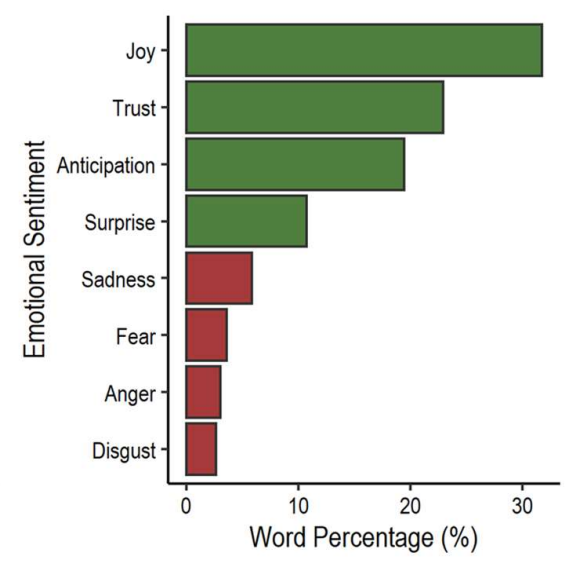

Figure 4. Cultural values of the entire BAMKP. A. Sentiment analysis of Google review words ranging from the most emotively positive $(+5)$ to the most emotively negative $(-5)$ words. B. Emotional sentiment analysis of Google review words.

PPGIS surveys found that the park features planned and present in BAMKP were generally valued as important (see Figure 5). The common and non-exclusive park features such as the bridges (93\% importance), shelters (93\%), fitness corners (89\%) and food and beverages (F\&B) outlets $(87 \%)$ were the most highly valued, likely for their widespread utility. The iconic naturalised river meandering through BAMKP was also among the most highly valued (92\%). The other ten more localised and specific park features found in either the Pond Gardens or River Plains were deemed of secondary and moderate importance (62-77\%).

The cultural values of these specific environmental spaces were also uncovered to be influenced by the park users' dominant park usage. For example, less Pond Gardens users (51\%) found the Recycle Hill located in the River Plains important whereas more River Plains users (77\%) acknowledged its value. Interestingly, it was also found that park users who dominantly frequented the River Plains generally reported higher valuations for all the BAMKP features.

When rescaling the analysis to inspect more closely on the cultural values of the CES, the PPGIS survey has highlighted its general high importance (see Figure 6). Using a Likert scale (Figure 6), all the CES in BAMKP scored a high average of 4.25 and ranged relatively high between 3.77 and 4.56. Of all the CES, the recreational (4.56) and relaxation (4.44) were the most highly valued followed by biodiversity (4.29), social (4.25) and aesthetic (4.21). The least culturally valued one was found to be related to education (3.77), since BAMKP was primarily designed as a recreational park [13] 
A.

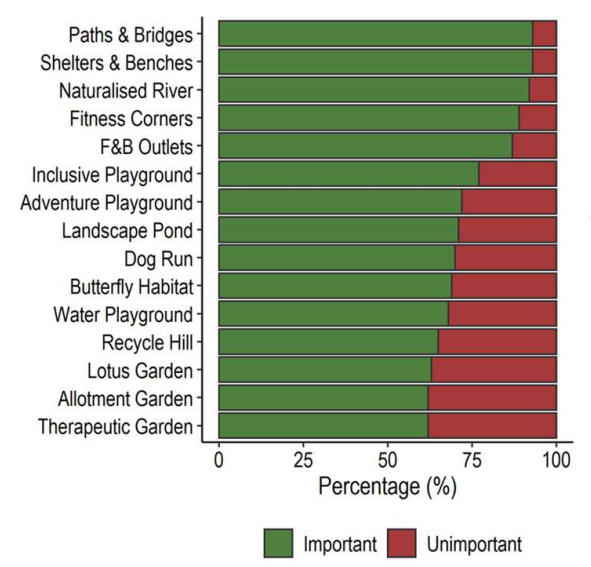

B.

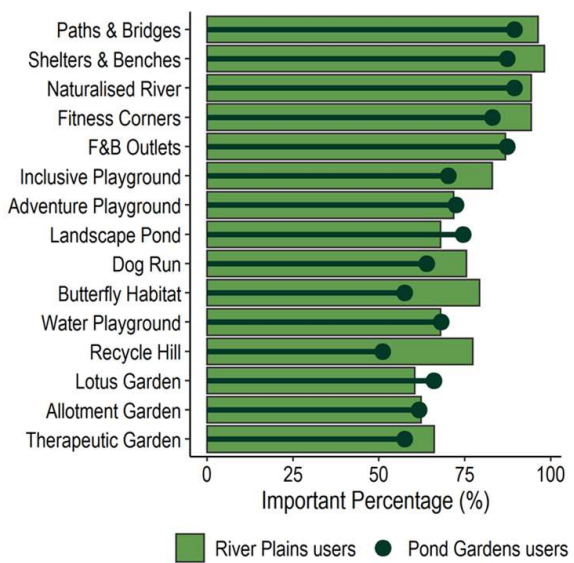

Figure 5. Cultural values of specific environmental spaces in BAMKP. A. Degree of importance and unimportance of park features by PPGIS participants. B. Degree of importance of park features by PPGIS participants according to their dominant park usage.

A.

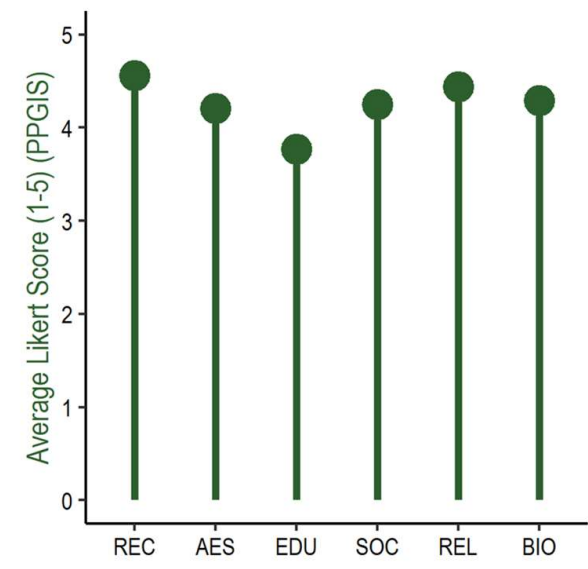

B.

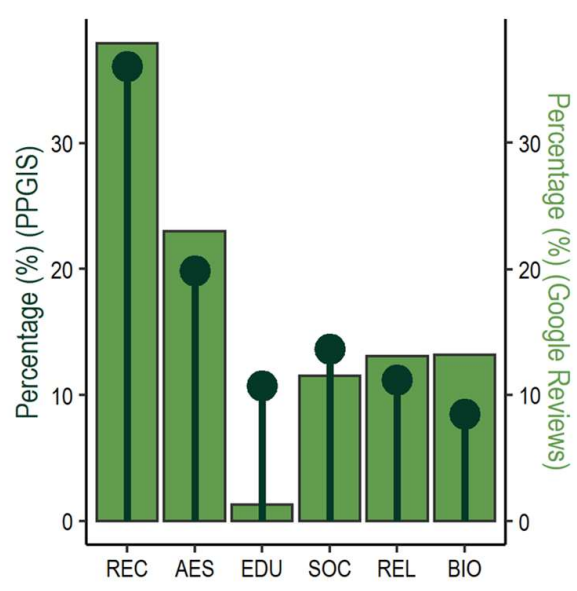

Figure 6. Cultural values and presence of CES in BAMKP. A. Cultural values of CES in BAMKP via a Likert scale where 1 and 5 represent the utmost unimportance and importance of CES to PPGIS participants respectively. B. Presence of CES in BAMKP via percentage of blobs mapped by PPGIS participants (left axis) and percentage of CES-related words from Google reviews (right axis). Abbreviations: REC - Recreation, AES - Aesthetic, EDU - Education, SOC - Social, REL - Relaxation, BIO - Biodiversity.

\subsection{Cultural Ecosystem Services}

\subsubsection{Relative Presence}

Although the PPGIS participants have ranked considerable importance to all the CES offered in BAMKP, their engagement with the CES was found to be more varied (see Figure 6). Using the number of blobs mapped by all participants for each respective CES as a proxy, the most present and engaged CES in BAMKP was recreation (36.1\%) followed by aesthetic (19.8\%). In the word occurrence frequency analysis of Google reviews, recreation $(37.9 \%)$ and aesthetic $(23.0 \%)$ were also the top two CES which could be attributed to its "beautiful $3 \mathrm{~km}$ meandering river with lush banks of wildflowers" which makes "it a popular choice for nearby residents for recreational 
activities" [13]. Popular recreational activities in BAMKP include walking, running, cycling, dancing, yoga and even Chinese martial arts [22]. Recreation has also been routinely and widely recognized as a dominant CES in many other UGS study areas [33].

From the PPGIS survey, except for the anomalous education CES (1.3\%), findings from the word occurrence frequency of Google reviews also shed a similar light for social, relaxation and biodiversity CES (11.5-13.2\%). However, education CES are likely still present in BAMKP as reported by the PPGIS participants $(10.7 \%)$, where some of them have have visited the park "with students/colleagues" as teachers or "with classmates" as students.

\subsubsection{Spatial Distribution}

Based on the PPGIS mapping of all six CES, heat maps were curated for all CES alongside each specific CES to show the extensiveness and concentration of CES present in BAMKP (see Figure 7). Generally, it was found that all the CES in BAMKP is well spread across the entire space of the parkdue to both the high utilisation of park spaces with amenities and the extensive network of pathways present throughout BAMKP. The localised CES hotspots also tend to be located near the renaturalised water features as these famed spots in BAMKP tend to have higher levels of social activities (Dreiseitl et al., 2015). More specifically, the hotspots coincided with prominent park features such as the McDonald's F\&B outlet, Recycle Hill and Therapeutic Garden. On the other hand, coldspots with an absence of CES were discovered to congregate near areas which were less accessible and equipped with fewer amenities.

Recreation and relaxation CES were found to be the most widespread throughout the park due to their dynamism which require participants to move about. As aesthetic, education, social and biodiversity CES tend to be more static, the spread of these CES throughout the park were only moderately expansive. Social CES is the least and tend to cover the central spaces of both the bisected parks since socialisation tends to require a highly static sitting environment, such as at shelters or F\&B outlets.

Similar to the concentration for all CES, the locations of CES hotspots for each specific CES were generally situated near renaturalised water features similar to the discovered popular park features like the McDonald's F\&B outlet (recreation, aesthetic, social and relaxation), Recycle Hill (recreation, aesthetic and relaxation) and Landscape Pond (recreation, aesthetic, education, relaxation). Anomalous and unique hotspots were also present for each CES, such as the two playgrounds and the community Allotment Garden for recreation CES. Distinct hotspots were also identified for education CES located near the Butterfly Habitat and a nearby shelter because of the informative displays and space for gathering. As for biodiversity CES, three notable anomalous hotspots were found at the bridge near the McDonald's F\&B outlet, Butterfly Habitat and Dog Run. The prime location of this bridge is near the popular McDonald's F\&B outlet offering sightings of wildlife such as the Purple Heron [34]. 


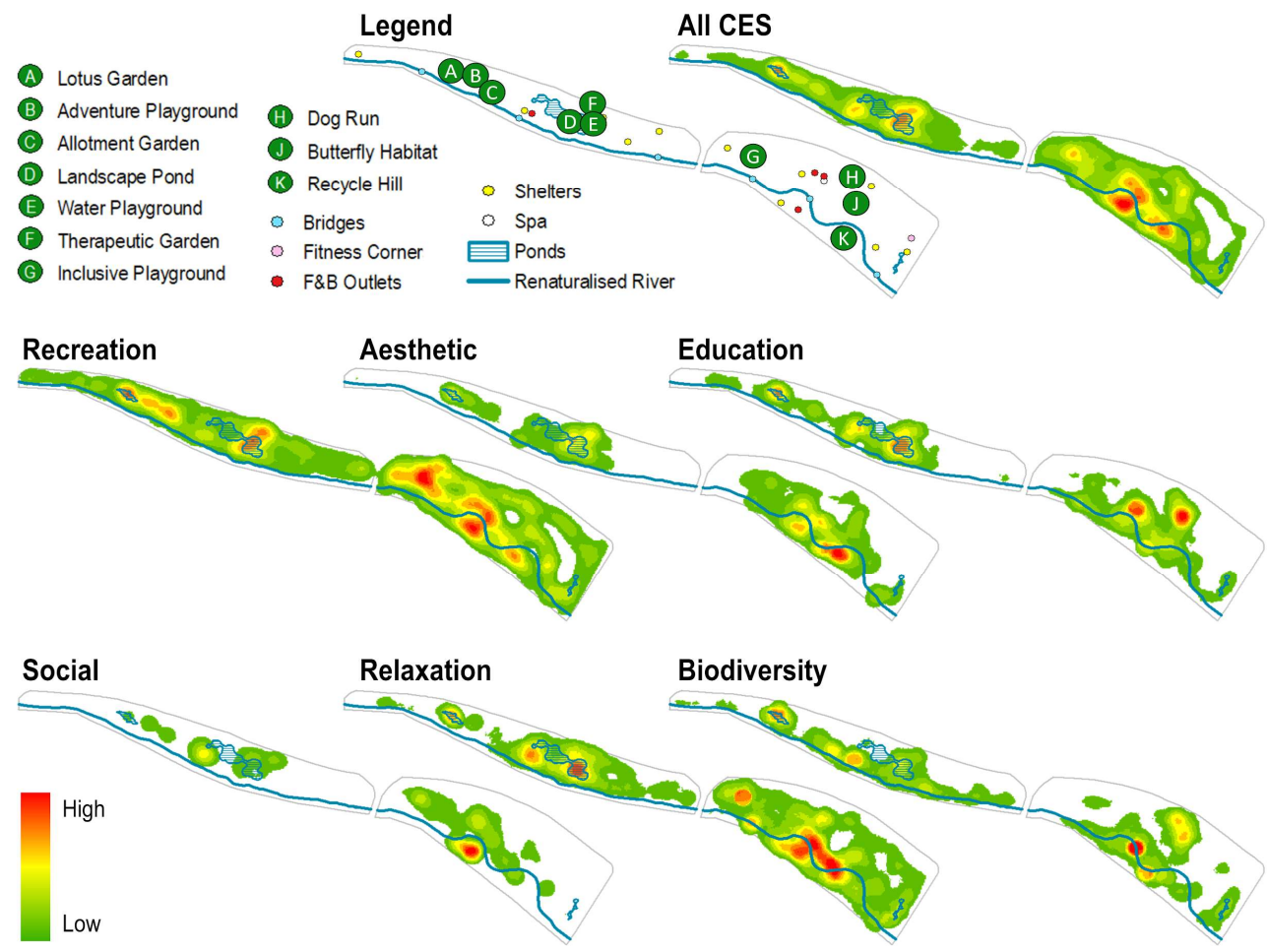

Figure 7. Spatial distribution of cultural ecosystem servies in Bishan-Ang Mo Kio Park

\subsubsection{Regional Distribution of Cultural Ecosystem Services Density}

Given that there are moderate differences in park characteristics along the North-South and East-West transects of the park, regional analysis of CES density was performed for these four cardinal directional regions (see Figure 1 and Table 2). The North-South transect presents proportional differences in blue-water and green-vegetated features, with the southern area being dominated by renaturalised blue-green features. On the other hand, the East-West bisection of the park was officially planned by park planners with the distinct and unique park features such as the Pond Gardens in the west and River Plains in the east.

Table 2. Regional distribution of CES density in BAMKP.

\begin{tabular}{lcccccccc} 
& \multicolumn{7}{c}{ CES Density (blobs/ha) } \\
& REC & AES & EDU & SOC & REL & BIO & ALL \\
\hline North (Green) & 873 & 370 & 215 & 318 & 232 & 155 & 2162 \\
South (Blue-Green) & 795 & 645 & 319 & 325 & 320 & 283 & 2687 \\
East (River Plains) & 906 & 503 & 243 & 370 & 295 & 187 & 2504 \\
West (Pond Gardens) & 767 & 415 & 263 & 254 & 220 & 216 & 2135 \\
\hline
\end{tabular}

Note: Southern BAMKP is defined to include areas (i) south of $30 \mathrm{~m}$ north of the river and (ii) within a $5 \mathrm{~m}$ buffer around ponds while northern BAMKP include the remaining areas (see Fig. 1). Eastern and western BAMKP are defined as the River Plains and Pond Gardens as officially planned by NParks respectively. Abbreviations: REC - Recreation, AES Aesthetic, EDU - Education, SOC - Social, REL - Relaxation, BIO - Biodiversity. 
Generally, it was found that the blue-green south of BAMKP has about $24 \%$ higher CES density than the chiefly green north. Most of the CES, except for recreation, has higher CES density in the southern blue-green part of the park than the green north. The southern dominance of CES density was the greatest for biodiversity ( $83 \%$ higher) and aesthetic ( $74 \%$ higher) and least for social ( $2 \%$ higher). Such a concentration of high CES density signify the success of the BAMKP's renaturalisation programme .

Recreation CES was the only anomaly where the northern green region is denser in CES than the blue-green south (10\% higher) due to environmental spaces,such as the pathways for jogging and cycling, the two playgrounds and community Allotment Garden.

The results from regional analysis of the two smaller bisected parks indicated that the eastern River Plains tend to possess higher CES density than the western Pond Gardens, at about $17 \%$ denser. Similarly, the majority of the CES was denser in presence in the eastern rather than the western park. While the proportionate differences between the East-West regions were not as significant as that between the North-South regions, social ( $46 \%$ higher) and relaxation CES (34\% higher) had the greatest regional disparity. The dominance of CES density in the eastern River Plains could be due to the park visitorship being higher there as compared to the western Pond Gardens (Dreiseitl et al., 2015) because of higher population density surrounding the eastern River Plains and proximity to Bishan metro station (Dreiseitl et al., 2015). The two anomalous CES with higher density in presence in the western River Plains were found to be education and biodiversity, hence the park features have more potential in gearing BAMKP towards the "City in Nature" vision.

\subsubsection{Spatial Correlations}

The CES spatial correlation was calculated using Jaccard's Index (Bonham-Carter, 2014) to determine the degree of spatial correlation between each of the CES (see Figure 8). Overall, as this research leans towards the social sciences, there is a moderately high degree of spatial correlation (coefficient value of 0.3 to 0.5 ) between all the CES pairings, except some biodiversity CES. . The most spatially similar pairing was found to be between recreation and aesthetic CES (0.49), followed by aesthetic-social (0.39), recreation-relaxation (0.38) and aesthetic-education (0.38). Generally, pairings with recreational and aesthetic CES yielded more spatially similar correlations. On the other hand, pairings with biodiversity CES generated the least spatially similar correlations, with biodiversity-social (0.25), biodiversity-relaxation (0.26) and biodiversity-education (0.28).

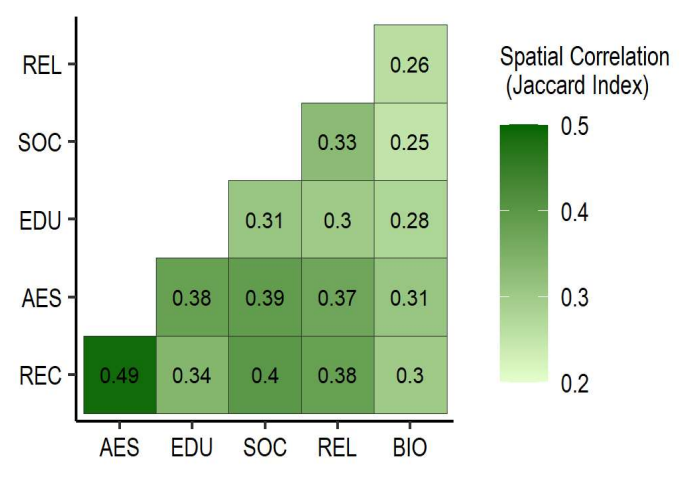

Figure 8. Spatial distribution of CES in BAMKP. Abbreviations: REC - Recreation, AES - Aesthetic, EDU - Education, SOC - Social, REL - Relaxation, BIO - Biodiversity. 


\subsection{Cultural Ecosystem Benefits}

From the PPGIS survey, participants generally reported a moderately high degree of CEB presence with an average score of 3.60 on a Likert scale (see Figure 9). The experiential benefits were the most present (3.87), followed by capabilities (3.66) and identities benefits (3.27). Similar findings from the occurrence frequency analysis of Google review words where a majority $81.1 \%$ of the CEB-related words were associated with experiential benefits. This is understandable due to the urban park being intentionally designed for experiential activities, such as exercising, playing, wildlife watching and photography [13]. The one-way ANOVA test yielded no statistically significant differences for the experiential benefits, suggesting the general universality of the experiential enjoyment that park users may benefit from BAMKP (Table S1).

On the other hand, the relatively lower presence of identities and capabilities CEB may be attributed to how these two types of benefits may require more sustained and repeated park visits (See Figure 9). . This is supported by findings from the one-way ANOVA test where residential proximity and park visit frequency were found to play a statistically significant role in one's identity CEB. People who lived central to the park and have visited the park frequently tend to report higher levels of benefits to their identity formation. However, $70 \%$ of the PPGIS participants have only visited BAMKP less than once a month or not at all in the past year. Such an infrequent park visits could lead to the relatively lower identity and capabilities CEB reported. Besides, Singapore's cityscape is generally blanketed with a variety of trees, shrubs and grasslands and everyday exposure could have already provided for identity and capabilities CEB, such as improvement of one's mental health [35] and weakened people's association of these CEB with BAMKP.

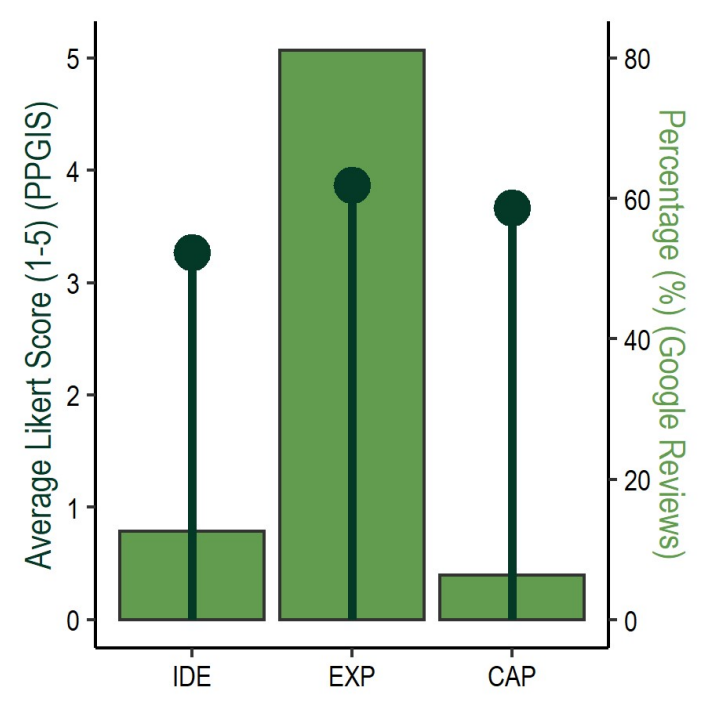

Figure 9. Presence of CEB in BAMKP via a Likert scale where 1 and 5 represent the utmost absence and presence of CEB enjoyed by PPGIS participants respectively (left axis) and percentage of CEBrelated words from Google reviews (right axis). Abbreviations: IDE - Identities, EXP - Experiences, CAP - Capabilities.

\subsection{Causal Relationshoips between Services and Benefits}

Understanding of CES and CEB relationship will enable planners to make more informed decisions on howpark spaces may influence the resultant CEB enjoyed [5]. Figure 9 demonstratesthe relation of CES spatial distribution and high presence of CEB. 
While in Fig. 10, when compared with the all CES heat map, the CES-CEB heat map for the experiences CEB is highly similar in terms of its spatial distribution and locations of hotspots. This reinforces that the experiential benefits of BAMKP were the most dominant among the three types of CEB.

On the other hand, for the categories of identities and capabilities CEB, the balance is skewed towards the Pond Gardens and slightly towards the River Plains respectively. Most of the CES relating to a high presence of identities CEB were found in the Pond Gardens, with hotspots around its unique key features such as Landscape Pond, Lotus Garden, Adventure Playground and a bridge that provides a scenic view of the naturalised river. As for the capabilities CEB, slightly more CES associated with high presence of capabilities CEB were found in the River Plains located near the McDonald's F\&B outlet, Recycle Hill and similarly bridges providing scenic views of BAMKP.

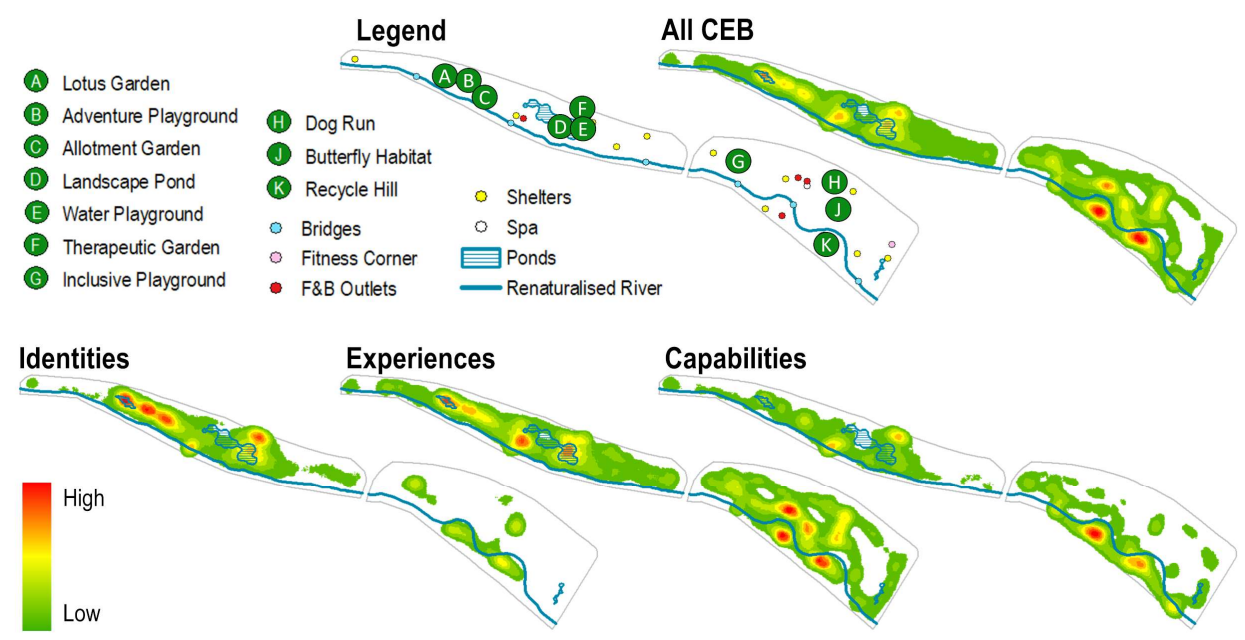

Figure 10. Spatial distribution of CES relating to high CEB enjoyment in BAMKP.

\section{Discussions}

\subsection{Policy Implications}

Generally, BAMKP is well received by park users as shown from the generally positive and highly important cultural values attached to the overall park, its features and services. The success of the renaturalised park was evidently shown through the reported wealth of CES present in BAMKP, especially for recreational and aesthetic CES (Dreiseitl et al., 2015). Congregations of CES hotspots were found near redesigned park features, especially the renaturalised water features [22]. The multipurposeness of environmental spaces provided a variety of synergised CES, as suggested by their moderately high spatial correlation. The high presence of CEB enjoyed by park users also compounded its success, most notably for the universally enjoyed experiential CEB via exercising [22].

However, the reported results also suggested the limitations of BAMKP in gearing towards the 'City in Nature' visiondue to lack in abundance and spatial spread of biodiversity and education CES in BAMKP $[13,14,23,24]$. These two CES are crucially important to "provide Singaporeans with a better quality of life while co-existing with flora and fauna on this island" [12]. By enhancing the biodiversity in parks, the chances of human-wildlife 
interactions may be enhanced $[3,4,36]$. However, it is important for these interactions to be positive as well, which then requires park users to have sufficient environmental knowledge and understanding of the parks' flora and fauna (Hwang \& Jain, 2021). Currently, as proxied by the Google reviews (see Fig. 6), the general public may be lacking awareness of the available educational opportunities afforded by BAMKP. The poor engagement with the important biodiversity and educational CES may hamper BAMKP in progressing to a rewilded park suitable for a 'City in Nature' [12].

Nevertheless, education and biodiversity CES is still accorded high importance by park users which supports further augmenting of more human-wildlife interactions in BAMKP. As such, five data-driven suggestions are recommended to inch BAMKP towards becoming a more rewilded park. Firstly, park spaces and features may be redesigned to incorporate wilder and more informative elements for general public usage (Lee, 2020). The former would likely be achieved with the rewilding plans already slated for BAMKP (NParks, n.d.-b). As for the latter, while current efforts do exist such as the occasional family tours (NParks, n.d.-f), increasing the frequency and publicity of these educational opportunities for the general publicand using mobile applications with interactive augmented reality elements, which complemented the C2C Trail (NParks, n.d.-d), may be implemented.

Secondly, local planners may consider expanding such renaturalisation northwards to enrich the diversity of CES which synergised with the popular recreational CES already present there [22]. By enabling park users to both engage in recreational activities whilst enjoying other CES, the overall park experience and CEB enjoyed would likely be enhanced. Thirdly, planners may consider enhancing visitorship to the western Pond Gardens, which was reportedly less frequented but richer in the crucial biodiversity and education CES [22] by improving accessibility to the park coupled with more affordable F\&B outlets like the ones in eastern River Plains. The adjacent Bright Hill metro station scheduled to start operating in 2021 [37] (Land Transport Authority, n.d.) and the recent launch of the C2C Trail stretching across both sections of BAMKP would also likely start improving park visitorship too $[23,24]$.

Furthermore, planners may emulate the successful naturalised Pond Garden features yielding high identities CEB for spatially targeted interventions in the poorer northern River Plains. Improvement of accessibility to the park to increase park visit frequency may also help to enhance identities CEB enjoyed. The diversification of CEB would be important to "provide Singaporeans with a better quality of life" [12] with the 'City in Nature' vision. Lastly, planners may also examine the feasibility to locate the various abovementioned suggestions at the reported CES coldspots, such as the northeast part of BAMKPto maximise park spaces available with more densely packed CES and CEB for park users. Park features that were deemed of less importance, such as the Therapeutic Garden, Allotment Garden and Lotus Garden, could be reviewed and refurbished accordingly towards the 'City in Nature' vision.

Overall, the redefined CES conceptual framework revealed a rich plethora of information ranging from the CES, CEB to cultural values of an UGS. The framework has provided high-quality actionable insights to support planners in their UGS management. As the shaping of environmental spaces is often directly under the purview of planners, planners will now understand how their actions may affect the availability of CES and enjoyment of CEB, consequently allowing them to make more informed decisions for preferred outcomes [3-5]. A reassessment using the framework performed afterwards can also help evaluate the effectiveness of any changes effected to improve the UGS. This paper, hence, implore future planners to consider employing the redefined CES conceptual framework to obtain more relational, data-driven and actionable insights to better support UGS management. 


\subsection{Methodological Implications}

Due to the limitations of online PPGIS surveys and social media text mining, this research would like to implore future CES research to deliberate on the following significant methodological considerations for more effective UGS management.

Firstly, it is important for future research to continue employing public participatory methods rather than having a singular reliance on the traditional top-down expert opinions of planners and researchers [1-4]. Only by supplementing professional opinions with the ground and bottom-up data obtained from the actual UGS users may a truer reality of the UGS be uncovered for more effective planning and management (Loc et al., 2015). This is especially crucial for the employment of CES as a conceptual backbone for research given its strong social dimension where the direct collection of data from the UGS users may reveal a more accurate presence of the services, benefits and valuations of an UGS. Engaging with these key stakeholders and beneficiaries of the UGS shouldbe ideally performed during the research design phase [1-4,19,20], This is an acknowledged limitation of this study is the survey questionnaire design was solely based on the researcher's extensive and frequent personal experiences with BAMKP. Thus, planners should consider collecting public-consulted datafor better understanding of the reality on the ground so as to make more informed decisions. This recommendation extends beyond the border of BAMK or Singapore, but also other sites as well, highlighting the necessity of science-policy interfaces.

Secondly, future research should deliberate on the choice of PPGIS tool employed to collect purposeful data. Of the various available options, Map-Me [28] was used e in this study to collect reflections of CES distributed throughout BAMKP. The affordances of Map-Me was tapped upon to allow participants to respond to spatial questions using a 'spray can' to add blobs onto a curated survey map [28] (refer to Supporting Information Fig. S4). This is advantageous as the general public's concept of space and place tend not to be reduced to simply points, lines and polygons as afforded by traditional PPGIS mapping tools [1-4]. However, Map-Me does have some limitations with its incompatibility with mobile devices to perform the survey. Future research should thus, carefully consider the various advantages and disadvantages of the available PPGIS tools, including financial cost and accessibility of data collection, to meet their research needs.

Thirdly, as "no single methodology can capture the total cultural value of any ecosystem" and the complexity of the relationship between CES, CEB and cultural values in relation to individual people, certain aspects of it might not be fully captured by the blindspots present in every research method [25]. Future studies should consider employing mixed methods to overcome possible methodological limitations and uncover a closer-to-reality truth of the UGS.. For instance, the method employed in this paper were able to very successfully capture the 'what' and 'where' of the CES but less able to explain the 'how' and 'why' for their presence. The PPGIS survey obtained from a limited sample size ( $\mathrm{n}=$ 100) with slightly skewed demographics may be less of a concern due to the validation by similar results from the sizable $(n=5,762)$ and more demographically balanced social media text mining of Google reviews. Hence, UGS planners should consider employing complementary mixed methods to augment the reliability of the findings in supporting UGS planning and decision-making.

Beside, deliberations should be made between balancing the accessibility and reliability of the data collection process. While it is ideal to augment both factors, in reality, some level of optimisation needs to be performed to calibrate the two seemingly inverse-related factors. For example, the administering of survey questionnaires online may be more convenient for both the planners and participants in terms of time and effort spent. However, the reliability of the data collected online may be likely undermined by 
potential lower response rate and mapping effort, especially for the spatial PPGIS questions [38].

Lastly, continuous monitoring of the constantly changing CES, CEB and cultural values in an UGS will enable urban planners to receive timely updates where they may better take data-driven mitigating actions to enact improvements (Matasov et al., 2020). As compared to static findings momentarily captured through one-off research, continuous monitoring may reflect truer evolving values in an UGS on a more temporally sensitive and longitudinal scale. Apart from continuous traditional surveying, urban planners can rely on more suitable platforms such as Maptionnaire (https://maptionnaire.com/) which allows real-time spatial data to be gathered from the public and presented in a more communicative manner. Places with greater access to more advanced technology might consider leveraging the Internet of Things with widespread sensors distributed across the UGS for continuous monitoring. Singapore could achieve this with the Smart Nation initiative where urban planning and management are to be supported with a plethora of information delivered from a shared network of sensors [39]. Singapore has the potential to synergise and drive both the Smart Nation and 'City in Nature' visions in tandem for complementary support. Other than static sensors, it could also be possible to deploy mobile sensors to collect spatially dynamic data since Singapore recent deployment of roving robot dog equipped with video analytic tools to estimate park visitorship in BAMKP [40]. Overall, future studies should carefully deliberate on the abovementioned methodological considerations to collect more credible data for constructive UGS management.

\section{Conclusion}

To encapsulate, this paper has sought to evaluate the operability of Tandarić et al.'s (2020) [5] redefined CES conceptual framework to support UGS planners in their decisionmaking and management, with a specific focus on Singapore's 'City in Nature' national initiative. BAMKP was utilised as a case study research area where the redefined CES approach formed the conceptual backbone in methodologically distilling the CES, CEB and cultural values of the park. PPGIS served as the primary method and provided spatial and non-spatial insights regarding the 'what' and 'where' CES were present in BAMKP, alongside CEB and cultural values information. To buttress and better validate the PPGIS findings, social media text mining analysis via Google reviews was also performed through occurrence frequency and sentiment analysis. Generally, it was found that BAMKP offered a wealth of CES and moderately high CEB for park users, especially with regards to recreational and aesthetic CES and experiential CEB. Moreover, park users also generally reported highly positive and important cultural values associated with BAMKP.

While BAMKP was reportedly a relatively successful renaturalised urban park, the usage of the redefined CES approach has also exposed various shortcomings of the park in gearing towards Singapore's 'City in Nature' vision. $=$. From the actionable insights obtained, five data-driven recommendations were provided: (i) design park spaces and features with wilder and more informative elements, (ii) expand blue-green naturalisation of the park northwards, (iii) improve accessibility and attractiveness of the western Pond Gardens richer in biodiversity and education CES, (iv) rebalance spread of identities and capabilities CEB by replicating success and (v) refurbish CES coldspots in conjunction with abovementioned suggestions to maximise park space. These suggestions would likely augment the readiness of BAMKP in inching closer towards the 'City in Nature' vision. 
It was evident from our study that the redefined CES conceptual framework has the potential to be researched further for it to be operationalised to better support planners in decision-making and management of UGS. This is because the CES approach doubly decouples CES into its component environmental spaces and cultural activities where their interactions then generate CEB. Planners may draw insights on how shaping of environmental spaces may influence the CES offered, the CEB enjoyed by UGS users and hence may make more data-driven and informed decisions. Rather than being statically fixed, the flexibility to choose relevant and relatable CES, CEB and cultural values to be studied further enhance the operability of the redefined CES approach.

Reflexivity was performed during and after the data collection and analysis. When using the redefined CES approach to study an UGS for management purposes, this paper would like to implore future research to deliberate on five methodological considerations: (i) employ public participatory methods to garner truer reflection of accurate data directly from users of the UGS, (ii) carefully consider on the choice of PPGIS tools based on their affordances, (iii) exercise mixed methods to uncover a diverse spectrum of the same data for closer-to-reality truth of an UGS, (iv) optimise and recalibrate between the accessibility and reliability of the data collection method and (v) consider the potential and feasibility of continuous monitoring to unravel temporally dynamic and longitudinal insights. Overall, this paper would recommend the employment of the redefined CES conceptual framework to generate relational, data-driven and actionable insights to better support UGS management in the future.

\section{References}

1. Loc, H. H., Diep, N. T. H., Tuan, V. T., \& Shimizu, Y. (2018a). An analytical approach in accounting for social values of ecosystem services in a Ramsar site: A case study in the Mekong Delta, Vietnam. Ecological Indicators, 89, 118-129.

2. Loc, H. H., Ballatore, T. J., Irvine, K. N., Diep, N. T. H., Tien, T. T. C., \& Shimizu, Y. (2018b). Socio-geographic Indicators to Evaluate Landscape Cultural Ecosystem Services: a case of Mekong Delta, Vietnam. Ecosystem services, 31, $527-542$.

3. Loc, H. H., Park, E., Thu, T. N., Diep, N. T. H., \& Can, N. T. (2021). An enhanced analytical framework of participatory GIS for ecosystem services assessment applied to a Ramsar wetland site in the Vietnam Mekong Delta. Ecosystem Services, $48,101245$.

4. Yee, J. Y., Loc, H. H., Le Poh, Y., Vo-Thanh, T., \& Park, E. (2021). Socio-geographical evaluation of ecosystem services in an ecotourism destination: PGIS application in Tram Chim National Park, Vietnam. Journal of Environmental Management, 291, 112656 .

5. Krellenberg, K., Artmann, M., Stanley, C., \& Hecht, R. (2021). What to do in, and what to expect from, urban green spacesIndicator-based approach to assess cultural ecosystem services. Urban Forestry \& Urban Greening, 59, 126986.

6. Tandarić, N., Ives, C. D., \& Watkins, C. (2020). Can we plan for urban cultural ecosystem services? Journal of Urban Ecology, 6(1). $1-17$.

7. Millennium Ecosystem Assessment. (2005). Ecosystems and human well-being: Synthesis. Island Press.

8. Campbell, L. K., Svendsen, E. S., Sonti, N. F., \& Johnson, M. L. (2016). A social assessment of urban parkland: Analyzing park use and meaning to inform management and resilience planning. Environmental Science \& Policy, 62, 34-44.

9. Loc, H. H., Irvine, K., Suwanarit, A., Vallikul, P., Likitswat, F., Sahavacharin, A., Sovann, P., \& Ha, L. (2020). Mainstreaming ecosystem services as public policy in South East Asia, from theory to practice. In Sustainability and Law (pp. 631-665). Springer.

10. Chan, K. M. A., Satterfield, T., \& Goldstein, J. (2012). Rethinking ecosystem services to better address and navigate cultural values. Ecological Economics, 74, 8-18.

11. Friess, D. A. (2017). Singapore as a long-term case study for tropical urban ecosystem services. Urban Ecosystems, 20(2), $277-291$.

12. Lee, D. (2020). Speech by 2M Desmond Lee at the Committee of Supply Debate 2020 - Transforming Singapore into a City of Nature. Ministry of National Development. Available online: https://www.mnd.gov.sg/newsroom/speeches/view/speech-by2m-desmond-lee-at-the-committee-of-supply-debate-2020---transforming-singapore-into-a-city-of-nature (accessed on $05 \mathrm{No}$ vember 2021)

13. NParks. (n.d.-a). Bishan-Ang Mo Kio Park. Available online https://www.nparks.gov.sg/gardens-parks-and-nature/parks-andnature-reserves/bishan---ang-mo-kio-park (accessed on 07 November 2021) 
14. NParks. (n.d.-b). Nature Ways. Available online: https://www.nparks.gov.sg/gardens-parks-and-nature/nature-ways (accessed on 11 November 2021)

15. Natural Capital Singapore. (n.d.). Available online: http://www.naturalcapital.sg/ (accessed on 05 November 2021)

16. McDonough, K., Hutchinson, S., Moore, T., \& Hutchinson, J. M. S. (2017). Analysis of publication trends in ecosystem services research. Ecosystem Services, 25, 82-88.

17. Brander, L., \& Eppink, F. (2015). The economics of ecosystems and biodiversity for Southeast Asia. Available online: http://www.teebweb.org/wp-content/uploads/2013/07/TECHNICAL-REPORT-ASEAN-TEEB-Scoping-Study.pdf (accessed on 12 November 2021)

18. Leeson, G. W. (2018). The Growth, Ageing and Urbanisation of our World. Journal of Population Ageing, 11(2), $107-115$.

19. Loc, H. H., Babel, M. S., Weesakul, S., Irvine, K. N., \& Duyen, P. M. (2015). Exploratory assessment of SUDS feasibility in Nhieu Loc-Thi Nghe Basin, Ho Chi Minh City, Vietnam. British Journal of Environment and Climate Change, 5(2), 91-103.

20. Loc, H. H., Duyen, P. M., Ballatore, T. J., Lan, N. H. M., \& Gupta, A. D. (2017). Applicability of sustainable urban drainage systems: an evaluation by multi-criteria analysis. Environment Systems and Decisions, 37(3), 332-343.

21. Nguyen, H. Q., Radhakrishnan, M., Bui, T. K. N., Tran, D. D., Ho, L. P., Tong, V. T., ... \& Loc, H. H. (2019). Evaluation of retrofitting responses to urban flood risk in Ho Chi Minh City using the motivation and ability (MOTA) framework. Sustainable Cities and Society, 47, 101465.

22. Dreiseitl, H., Leonardsen, J. A., \& Wanschura, B. (2015). Cost-benefit analysis of Bishan-Ang Mo Kio Park. Available online: https://ramboll.com/megatrend/ /media/FAFD295CD2A04A598C132CB72BA996A8.ashx (accessed on 05 November 2021)

23. NParks. (n.d.-c). Park Connector Network. NParks. Available online: https://www.nparks.gov.sg/gardens-parks-and-nature/park-connector-network (accessed on 06 November 2021)

24. NParks. (n.d.-d). NParks Coast-to-Coast Trail. NParks. Available online: https://www.nparks.gov.sg/gardens-parks-and-nature/parks-and-nature-reserves/coast-to-coast (accessed on 06 November 2021)

25. Cabana, D., Ryfield, F., Crowe, T. P., \& Brannigan, J. (2020). Evaluating and communicating cultural ecosystem services. Ecosystem Services, 42, 101085.

26. Dai, P., Zhang, S., Chen, Z., Gong, Y., \& Hou, H. (2019). Perceptions of cultural ecosystem services in urban parks based on social network data. Sustainability, 11(19), 5386.

27. Richards, D. R., \& Friess, D. A. (2015). A rapid indicator of cultural ecosystem service usage at a fine spatial scale: Content analysis of social media photographs. Ecological Indicators, 53, 187-195.

28. Huck, J., Whyatt, D., \& Coulton, P. (2014). Spraycan: A PPGIS for capturing imprecise notions of place. Applied Geography, 55, 229-237.

29. Bonham-Carter, G. F. (2014). Tools for map analysis: Map pairs. In Geographic Information Systems for geoscientists: Modelling with GIS (Vol. 13). Elsevier.

30. R Core Team. (2020). R: A language and environment for statistical computing. In R Foundation for Statistical Computing. Available online: https://www.R-project.org/

31. Nielsen, F. Å. (2011, May 30). A new ANEW: Evaluation of a word list for sentiment analysis in microblogs. ESWC2011 Workshop on 'Making Sense of Microposts': Big things come in small packages, Heraklion, Crete.

32. Mohammad, S., \& Turney, P. (2010, June 5). Emotions evoked by common words and phrases: Using mechanical turk to create an emotion lexicon. NAACL HLT 2010 Workshop on Computational Approaches to Analysis and Generation of Emotion in Text, Los Angeles, CA.

33. Milcu, A. I., Hanspach, J., Abson, D., \& Fischer, J. (2013). Cultural ecosystem services: A literature review and prospects for future research. Ecology and Society, 18(3).

34. NParks. (n.d.-e). Your guide to Bishan-Ang Mo Kio Park. NParks. Available online: https://www.nparks.gov.sg/-/media/nparks-real-content/gardens-parks-and-nature/diy-walk/diy-walk-pdf-files/bishan-amkpark.pdf?la=en\&hash=F0755F963C895EDFDB17BDBE5B8ACE09DE92B0E1 (accessed on 13 November 2021)

35. Kua, E. H., \& Sia, A. (2017). Green Environment and Mental Health in the City. In N. Okkels, C. B. Kristiansen, \& P. MunkJørgensen (Eds.), Mental Health and Illness in the City (pp. 445-464). Springer Singapore.

36. Hwang, Y. H., \& Jain, A. (2021). Landscape design approaches to enhance human-wildlife interactions in a compact tropical city. Journal of Urban Ecology, 7(1). 
37. Land Transport Authority. (n.d.). Thomson-East Coast Line. Available online: https://www.lta.gov.sg/content/ltagov/en/upcoming_projects/rail expansion/thomson_east_coast_line.html (accessed on 02 December 2021).

38. Brown, G. (2017). A review of sampling effects and response bias in internet participatory mapping (PPGIS/PGIS/VGI). Transactions in GIS, 21(1), 39-56.

39. GovTech. (n.d.). Smart Nation Sensor Platform. Available online: https://www.tech.gov.sg/scewc2019/snsp?utm medium=recommender_3\&utm_source=aHR0cHM6Ly93d3cudGVjaC5nb3Yuc2cvcHJvZHVjdHMtYW5kLXNlcnZpY2VzL3NtYXJ0LW5hdGlvbi1zZW5zb3ItcGxhdGZvcm0v\&utm_content=aHR0cHM6Ly93d3cudGVjaC5nb3Yuc2cvc2Nld2MyMDE5L3Nuc3A=. (Accessed on 05 December 2021)

40. GovTech. (2020). NParks and SNDGG trial SPOT robot for safe distancing operations at Bishan-Ang Mo Kio Park. Available onlije: https://www.tech.gov.sg/media/media-releases/spot-robot-trial-for-safe-distancing-operations. (Accessed on 07 December 2021) 